\title{
ASSESSING THE ANTECEDENTS OF NATIONAL HEALTH INSURANCE SCHEME (NHIS) ENROLLMENT IN GHANA: THE PERSPECTIVE OF RURAL DWELLERS
}

\author{
Minkah Andrews Yaw ${ }^{1^{*}}$, Agyemang Prempeh Fredua Sylvester ${ }^{1}$ \\ Emmanuel Bosompem Boadi ${ }^{2 *}$, Isaac Amankwaa Adu ${ }^{1}$ \\ ${ }^{I}$ School of Management, Jiangsu University, Zhenjiang 212013, P.R. China. \\ ${ }^{2}$ School of Public Administration, Hohai University, Nanjing 202001, P.R. China.
}

Corresponding Author: Minkah Andrews Yaw*, Emmanuel Bosompem Boadi*

Article DOI: $\underline{\text { https://doi.org/10.36713/epra9591 }}$

DOI No: 10.36713/epra9591

\begin{abstract}
The purpose of this research is to assess the factors that affect National Health Insurance Scheme (NHIS) enrollment in Ghana. Using convenience sampling method, 200 completed data were analyzed. The Statistical Package for Social Sciences (SPSS 25) was used in analyzing the relationships between the Independent variables and the dependent variable. Findings from the study indicated that there is a reasonable positive linear relationship between Enrollment Drive Features (Independent variables) and NHIS Enrollment (Dependent). Based on the findings, it is concluded that, a comprehensive package and awareness of a health insurance guarantee higher enrollment. The study recommends that the National Health Insurance Authority (NHIA) and its affiliate offices intensify the education and sensitization program about the scheme, its role and the feedback from the public.
\end{abstract}

KEYWORDS: National Health Insurance Scheme; Enrollment; Rural dwellers; Enrollment Drive Features

\section{INTRODUCTION}

Ghana has made universal coverage of health care her top most priority, defined as 'access to adequate health care for all at a reasonably low price', of health care and has therefore enacted policies and programs to attain this objective. A number of health financing reforms have been executed meant to increase the general resources to the health sector and ensuring fairly allocation, the most recent of such reform is the National Health Insurance Scheme (NHIS), which seeks to enhance social health protection. Preceding to the formation of the NHIS in 2003, Ghana carried out most of the known healthcare financing machineries including general tax and donor funding, 'cash and carry' payments, and community-based health insurance schemes (Freeman, 2016). To cushion the burden of down-payment for health care, the government through its executive powers introduced an exclusions policy targeted at children under the age of 5, pre-natal care for pregnant women, the indigent and paupers, the elderly, and for some disease-specific services (Government of Ghana/SAPRI, 2001; Sulzbach et al., 2014; Singleton, 2015). Despite having a relatively comprehensive policy, there was considerable evidence that the exclusion policy was poorly funded and executed as many of those who should have enjoyed the exemption did not receive them (Sawadogo et al., 2017; Geng et al., 2018).

Notwithstanding this seemingly impressive financing structure, there is a pragmatic evidence of low enrollment, but there exists deficiency of information in the logical reasons, particularly regarding how poor people and low wage groups who are the primary target population for realizing the quality in the health care system have benefited from the scheme. Just $36 \%$ of the population are covered following a time of the scheme introduction, suggesting the universal health coverage status has not yet been accomplished (Oxfam, 2018). The 
study provided consistent data that was informative and instrumental to the National Health Insurance Authority (NHIA) and interested parties on the subject matter. It will also add to the existing body of knowledge in serving as locus to support subsequent researchers on the same or related topics; that is factors which affect National Health Insurance Schemes' enrollment. The recommendations of this research work can also serve as a guide for policy makers and governments in making informed policies on socio-economic factors that affect the enrollment of the NHIS in the country. Adopting a rural and relocated community perception make this paper the first of it kind and would help researchers and policy makers to reevaluate the policies on these vulnerable groups, while filling this gap in literature. Therefore, this study seeks to find out the factors that affect people' $\mathrm{s}$ decision to enroll on the National Health Insurance Scheme in Ghana.

\section{LITERATURE REVIEW}

A greater number of studies have been conducted in recent years on the patronage of health insurance. Sulzbach (2014) in their study revealed that household head characteristics (older age, female gender, higher education, and employment) forecast insurance enrollment at the household level, whereas these factors plus family wealth increased the likelihood of enrolment at the individual level. With regard to patronizing health insurance, those who are liable to illness were more likely to participate than their counterparts. Of course, persons in the educated circles and those who are prone to disease are more likely to patronize health insurance schemes than their counterparts because they have impartial understanding and experience of the scheme to be able to enjoy the benefits.

Jehu-Appiah (2017) noted that insights about provider schemes and community attributes play an imperative part, although there was a varying distinction in household decision to voluntarily enroll and remain enrolled on an insurance schemes. Policy makers were advised to embrace household taught as potential hindrances or enablers to enrollment and invest in understanding them in their design of interventions to stimulate membership. With a household survey of 3301 and 13865 individuals, the study results postulated that scheme factors have the strongest link with voluntary enrollment and retention decisions in the national health insurance scheme. Precisely, these relate to benefits, convenience and price of NHIS. At the same time, while family had positive perception with regard to technical quality of care, benefits of NHIS, the convenience of NHIS administration, and had appropriate community beliefs and attitudes, they were negative about the price of NHIS, provider attitudes, and peer pressure. People who have not enrolled unto a health insurance were more negative than the insured about benefits, convenience, and price of NHIS. If indeed household and individual perception about schemes do affect enrollment and retention in the scheme, then NHIA must invest education and awareness creation in order to maintain positive perceptions about the scheme. However, an individual perception is just one of the many factors that combine to affect enrollment positively or negatively. Again, it stands to reason that those who are insured are more positive about the benefits than those who are not, this is because it is that positivity that influences their decision to register and subsequently renew their membership and vice versa.

Again, Varatharagan (2016) their work noted that where the insurance scheme focused primarily on satisfying the needs of the poor and providing social health protection based on the values of equity, solidarity, risk sharing, cross-subsidization, reinsurance, client and community ownership, value for money, good governance, and transparency in the health care delivery, NHIS coverage is thus prominent in the most disadvantaged district, where there is a higher cases of poverty, lower levels of female education and lesser health care facilities and where the needs of the pregnant women and the elderly may not be met.

While some research may predict higher enrollment and participation for people with higher income, there is no doubt that is associated more with those working in the formal sector and live in the urban areas. As Varatharagan (2016), stated, poorer people in the rural setting who understand the benefits attached to health insurance are reliant on these schemes for health services just because they may not be able to afford payment for their services when they need it most. However, the influence that knowledge about the scheme has on patronage in the rural communities cannot be overemphasized. Hence, even though enrollment may be higher in a rural setting, it is dependent more on the knowledge and understanding that rural people have other than the factors noted by Varatharagan and others.

He \& Nolen (2018) also asserted that, there is a significant positive relationship between income and education on health care demand. Commonly, higher income decreases the opportunity cost attributed with the purchase of health insurance. Thus, increases in income and education are expected to increase the likelihood of patronizing health insurance. The effects of demographic and economic factors such as age, marital status, employment and gender on health insurance have been studied variously.

Married respondents are more likely to patronize an insurance coverage (Trujillo, 2017; Liu \& Chen, 2015). Those employed are also more likely to enroll unto an insurance coverage (Saltzman, 2018; Savage \& Wright, 2015; Ratner et al, 2018) 
Harmon and Nolan (20014) highlighted that marital status had a significantly positive impact on health insurance demand. In Ghana's NHIS, children below 18 years, whose parents or caretakers pay their own contributions, are excluded from paying any contribution. Thus, married couples may demand insurance in order to cover their children and also tend to be more averse to the risk of overwhelming health expenditures. Based on the above discussion, it can be concluded that this study is enriched with challenges facing people in patronizing National Health Insurance as well as the variables that influence enrollment in a health insurance scheme. However, most of these researches focused on privately run insurance schemes as against governmentrun insurance schemes. More often than not, government-run insurance schemes are affordable and are targeted at the poor. Therefore, if most research indicates a positive relationship between income and patronage, then it can be assumed that they are appropriate to areas where the premiums are high and are targeted at those who can afford such schemes. In Ghana where the main insurance scheme is government-run, this seems to be the opposite.

Wang et al. (2015) identify that in rural China the inability of farmers to pay premiums is a major limitation to enrollment. Similarly, Criel \& Waelkens (2013) reveal that the declining subscriptions to the Maliando Mutual Health Insurance Scheme in Guinea-Conakry are as a result of the inability of people to make payments of their premiums. Furthermore, In Ethiopia, Asfaw \& Braun (2014) found that enrollment in community health insurance remains low due to the inability to pay premiums. Basaza et al. (2018) also confirm the role of the inability to afford premium as significant in Uganda. Sulzbach et al. (2015) find a relationship between the inability to afford premiums and low enrollment in the Nkoranza and Kwahu Districts in Ghana. In Kenya, high premiums and inflexible premium collection schedules limit enrollment (Mathauer et al., 2018).

Inefficiencies and operational difficulties in the NHIS's administration have also been identified to contribute to low enrollment in Ghana (Jehu-Appiah et al., 2017). These related to membership registration, insurance cards production and distribution. Members had to wait for a period (between three to six months) before they received their membership cards. The delays discouraged enrollment, though the idea was to prevent adverse selection. 22 Institutional rigidities also accounted for low enrollment in the Jos City in Nigeria (Onyedibe et al., 2017). In some parts of rural China some community insurance schemes signed up members only once in a year and on a particular day. Those who decided to join later were not admitted. This rigidity was found to keep a significant number of potential members outside the scheme (Carrin, 2016).

Moreover, poor quality care of healthcare delivery to the insured may explain low enrollment. This may relate to long waiting periods for healthcare, excessive prescription, poor referral systems, and differential treatment based on the socio-economic and insurance membership status. Preferential treatment given to the uninsured as against that received by the insured is a disincentive to enrollment. A case on point is identified by De Allegri et al., (2017) and (Dalinjong \& Laar (2016) in the Nouna District in Burkina Faso and the Builsa and Bolgatanga Districts in Ghana respectively where some insured experienced long waiting hours for health care, verbal abuse and discrimination in favor of those who make upfront payment. The insured expressed dissatisfaction with the attitude of health workers. Again, some scheme members reported that they were not well examined by doctors as they saw them as not making direct contributions to the health cost financing of the providers.

The following hypothesis were therefore formulated:

H1: Health Care Delivery System has a positive and significant impact on NHIS Enrollment.

H2: Level of Income has a positive and significant impact on NHIS Enrollment

H3: Risk Perception and Health seeking behavior has a positive and significant impact on NHIS Enrollment

H4: Availability of Health Care Facilities has positive and significant impact on NHIS Enrollment.

\section{METHOD}

The research was conducted in Kokoteasua, Obuasi, Ghana. A relocated village to make way for Gold mining waste dump. Out of the total population, persons above the age, 18 were involved in the study. The research work adopted a descriptive and an exploratory research designs. These research designs were used to gather and analyze data in establishing the relationships between the constructs. The quantitative research method was employed to offer a clear description of the health insurance scheme and factors that affect its enrollment in Ghana.

Since this study attempts to identify the factors that affect NHIS Patronage in Kokoteasua, a survey research design was employed because it gives the researcher the opportunity to sample people's opinion and obtain comment or information from a significant number of respondents. It is also noted that the sole aim of survey study is to examine current opinions, behaviour and other characteristics of a group (Onodugo, Ugwuonah, \& Ebinne, 2010).

Questionnaires were developed to gather primary data from respondents to obtain information on how 
availability of health care facilities and health care delivery system affect NHIS enrollment and how a person's level of income affect NHIS enrollment, how risk perception and health seeking behavior affect NHIS enrollment. This research study employed cross-sectional multiple regression model in the analysis by looking out for the factors that affect NHIS Enrollment in Ghana. This study contains one (1) dependent variable and four (4) independent variables. Multiple regression analysis enabled hypotheses H1, H2, H3and H4 to be tested.

The variable $\mathrm{Y}$ is titled as the "dependent variable" which is denoted as NHIS Enrollment.

The independent variables (enrollment drive features) were therefore given application-based names such as health care delivery system $\mathrm{X} 1$, level of income $\mathrm{X} 2$, risk perception and health seeking behavior $\mathrm{X} 3$, and availability of health care facilities $\mathrm{X} 4$. The model is expressed as: $\mathrm{Y}=\beta 0+\beta 1 \mathrm{X} 1+\beta 2 \mathrm{X} 2+\beta 3 \mathrm{X} 3+\beta 4 \mathrm{X} 4+\mu$

\section{RESULTS}

Table 1: Respondents' Social Profiles

\begin{tabular}{lcll}
\hline Variables & Characteristics & Frequency & Percentage \\
\hline Gender & Male & 104 & 52 \\
& Female & 96 & 48 \\
Age & $18-35$ & 65 & 32.5 \\
& $36-45$ & 23 & 11.5 \\
\multirow{4}{*}{ Marital Status } & $46-59$ & 42 & 21.0 \\
& 60 and above & 70 & 35.0 \\
Employment & Married & 86 & 43.0 \\
& Single & 114 & 57.0 \\
& Self Employed & 32 & 16.0 \\
& Wage Employed & 84 & 42.0 \\
Membership of NHIS & Student & 64 & 32.0 \\
& Unemployed & 20 & 10.0 \\
& Registered & 105 & 52.5 \\
& Unregistered & 95 & 47.5 \\
\hline
\end{tabular}

Out of the 200 respondents $52 \%$ are males, $53.3 \%$ are married, $35 \%$ are above 45 years.

Factor Analysis and Reliability

A Cronbach's Alpha test was run to test the questionnaire's reliability. The table below shows that general calculated Cronbach's alpha for the study is 0.931 (table 2). This indicates that there is high reliability in the instrument used. The table below shows the results of the reliability test.

Table 2: Reliability Statistics of the Data

Table 3: Validity Statistics of the Data.

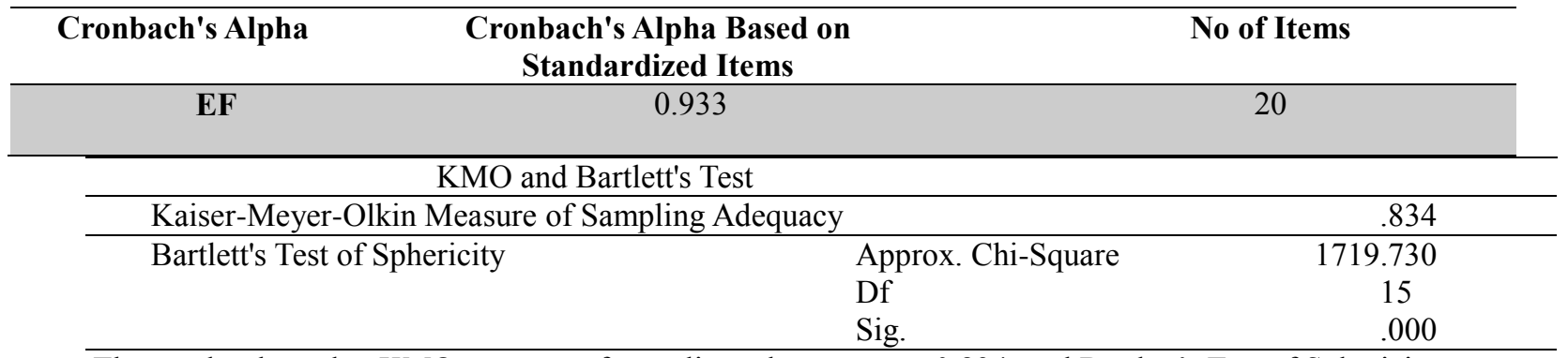

The results show that KMO measure of sampling adequacy was 0.834 , and Bartlett's Test of Sphericity was significant at $\mathrm{p}<0.001$, depicting the data was suitable for factor analysis.

\section{Correlation Analysis}

The results from the table 4 below shows that there is a positive correlation that exist between the independent variables namely: (health care delivery system, level of income, risk perception and availability of healthcare facilities) and the Dependent variable (NHIS enrollment).

Table 4: Correlation Matrix

\begin{tabular}{lccccc}
\hline \multicolumn{1}{c}{ Model } & $\begin{array}{l}\text { Health Care } \\
\text { Delivery System }\end{array}$ & $\begin{array}{l}\text { Level of } \\
\text { Income }\end{array}$ & $\begin{array}{l}\text { Risk } \\
\text { Perception }\end{array}$ & $\begin{array}{l}\text { Availability of } \\
\text { facilities }\end{array}$ & $\begin{array}{l}\text { NHIS } \\
\text { Enrollment }\end{array}$ \\
\hline $\begin{array}{l}\text { HealthCare Delivery } \\
\text { System } \\
\text { Level of Income }\end{array}$ & 1 & & & & \\
\hline
\end{tabular}




\begin{tabular}{lccccc}
\hline Risk Perception & .450 & .164 & 1 & & \\
Availability of Facilities & .067 & .285 & .416 & 1 & 1 \\
NHIS Enrollment & $.568^{* *}$ & $.711^{* *}$ & $.476^{* *}$ & $.661^{* *}$ & 1 \\
\hline
\end{tabular}

\section{REGRESSION ANALYSIS}

Based on the observations from the results of Beta coefficients and P-values, availability of health care facilities appear to be the strongest predictor of NHIS enrollment followed by Level of Income, and the next is risk perception and health seeking behavior, with health care delivery system being the least predictor of NHIS enrollment. Table 5 below shows the results of the relationship between the independent variables and the dependent variables.

Table 5. Regression of Enrollment Drive Features on NHIS Enrollment

\begin{tabular}{lccccc}
\hline \multicolumn{1}{c}{ Model } & $\begin{array}{l}\text { Unstandardized } \\
\text { Coefficients } \\
\text { Beta }\end{array}$ & $\begin{array}{l}\text { Std. } \\
\text { Error }\end{array}$ & $\begin{array}{l}\text { Standardized } \\
\text { Coefficients } \\
\text { Beta }\end{array}$ & T & Sig. \\
\hline $\begin{array}{l}\text { (Constant) } \\
\text { Healthcare Delivery }\end{array}$ & .359 & .123 & & 2.919 & .004 \\
System X1 & .053 & .047 & .056 & 1.128 & .000 \\
Level of Income X2 & .196 & & & & .006 \\
Risk Perception X3 & .138 & .070 & .192 & 2.789 & .001 \\
Availability of healthcare & .862 & .041 & .152 & 3.363 & .000
\end{tabular}

facilities $\mathrm{X} 4$

$R$ value

$.843 \mathrm{a}$

R-square value

Adjusted R-square

.706

Y=Dependent variable (NHIS Enrollment)

\section{FINDINGS}

These results confirm the study hypothesis (H1) that Health Care Delivery System has a positive and significant impact on NHIS Enrollment. This study is synonymous to the study by Jehu-Appiah (2017) who postulated that perceptions of people about health insurance scheme, service providers and disease causation have an impact on patronage. Negative perceptions decrease enrollment. Knowledge about health insurance schemes may be associated to the premium rate, suitability of the service provided by health workers and benefit package. Perceived low premiums and effective service delivery increases affordability and this has tendency of increasing enrollment. Moreover, the trust in insurance schemes relates to the assurance that members can actually depend on such schemes for financial assistance when they experience health shocks. The inability of an insurance scheme to provide to its subscribers when members are in need is likely to grind down trust, thereby restraining enrollment (De Bock \& Gelade, 2012).

Hypotheses $\mathrm{H} 2$ is confirmed that Level of Income has a positive and significant impact on NHIS enrollment. Again, the findings of this study is found to be similar to a study done by other researchers. Income has been identified to have a robust relationship with enrollment. All things being equal, higher incomes increase the ability to pay premiums, thereby increasing patronage unto the health insurance scheme. JehuAppiah (2017) has shown that income plays an imperative role as a determining factor of enrollment. Income is closely related to employment and so the employed may have a higher probability to enroll than the unemployed. As income increases and unemployment decreases, people are more willing to patronize health insurance (Asenso-Okyere et el., 2010).

These results endorse the study hypothesis (H3) that Risk Perception and Health Seeking Behavior has a positive and significant impact on NHIS enrollment. The poor and low income groups are more likely to take health insurance because they are more risk-averse than the higher income groups (Monheit \& Vistnes, 2016). These groups tend to have a higher aversion for risk and may sacrifice satisfying consumption for patronizing health insurance in order to protect their limited assets against tragic health expenditure as it can push them further below the point of survival. Additionally, the individual's self-assessment of health affects the decision to use health insurance. Jowett (2017) asserts that a person who assesses himself as healthy might be less willing to 
take health insurance than one who is less healthy. Furthermore, community and cultural beliefs about diseases causation can have an effect on enrollment. People who associate disease causation with spirituality may not take part in health insurance (De Allegri et al., 2016). Osei-Akoto \& Adamba (2017) assert that a strong belief and reliance on God and prayers for preventive health can reduce demand for health insurance, likewise the belief that buying health insurance implies inviting sickness (Baidoo \& Buss, 2012).

Therefore hypotheses $\mathrm{H} 4$ is confirmed that Availability of Health Care Facilities has positive and significant impact on NHIS enrollment. Long distance from a health facility or a health service provider translates into a high rate of amount of seeking health care which will be borne by the insured. Among the insured in the Self-Employed Women Association health insurance scheme in Uganda, members complained that the cost of transportation to a health facility discouraged them from utilizing health services, even though they had insurance (Morestin \& Ridde, 2019). Similarly, in the Asante-Akim South District in Ghana, there exist a negative association between long distance from a health care facility and insurance coverage. Enrollment is low among populations living further from a health facility (Sarpong et al., 2018).

\section{CONCLUSION}

The study conducted contained 200 respondents and a factor analysis along with multiple regression was run. The findings demonstrated a reasonable positive linear relationship between enrollment drive features and NHIS enrollment in Ghana. With regards to all the components of enrollment drive features i.e. independent variables, there exist a significant positive relationship between the components and NHIS enrollment. The study urges the NHIA to adopt mechanism in addition to constant monitoring of the scheme providers and training of health officials and eliminate the top-bottom approach of the scheme to bottom-up approach method. The study therefore recommends that, scheme managers should reduce premium rate as the majority of subscribers fall in the informal sector. These informal sector workers classified as mostly the poor in the community. Hence a higher fee, will force them to resort to self-treatment. The study only selected one community purposively for the research. The study identified health care delivery system, level of income, availability of health care facilities and risk perception and health seeking behavior of the scheme as areas of concern. Also, further research is also needed into how household characteristics affects ones enrollment drive unto a health insurance scheme.

Conflicts of Interest

The authors declare that they have no competing interests.

\section{REFERENCE}

1. Aboh, I. (2020). Perceptions of government stakeholders on ageing and assisted care in the Cape Coast Municipal Area. Advances in Social Sciences Research Journal, 7(4), 71-86. https://doi.org/10.14738/assrj.74.8013

2. Adamba, C (2017). The Thrills and Tears of national health insurance scheme card holders in Ghana.

3. Alan C. $M$ \& Jessica P.V (2014), "Health insurance enrollment decisions: preferences for coverage, worker sorting, and insurance take up." Working paper 12429.

4. Appiah, J. C., Household Perceptions and their implications for enrollment in the national health insurance scheme in Ghana. Health policy planning, 2017.

5. Arhin-Tenkorang D; (2015), "Mobilizing resources for health: the case study for user fees revisited", working paper no.81, Harvard University.

6. Asfaw, A. \& V.J. Braun. 2014. Can community health insurance shield the poor against the downside health effects of economic reforms? The case of rural Ethiopia. Health Policy, 70. 97-108

7. Atim C. \& Sock, M. (2014). An External Evaluation of the Nkoranza Community Financing Health Insurance Scheme, Bethesda: Partnership for Health Reforms.

8. Atim, C. \& S., Apoya P., et al. (2016). A survey of health financing schemes in Ghana. Bethesda, MD: Partners for health reform plus, Abt Associate Inc.

9. Basaza, R. et al. 2018. Community health insurance in Uganda: why does enrolment remain low? A view from beneath. Health Policy, 87. 172-184.

10. Basaza, R. et al. 2017. Low enrolment in Ugandan community-based insurance schemes: underlying causes and policy implications. Health Services Research, 7(3).

11. Carrin, G., Doetinchem, O., Kirigia, J., Mathauer, I., \& Musango, L. (2018). Social health insurance: how feasible is its expansion in the African region? Development issues, 10, 2.

12. Carrin, G. 2016. Social health insurance in developing countries: A continuing challenge. International Social Security Review, 55(2). 57-69.

13. Criel, B. \& P.M. Waelkens. 2013. Declining subscriptions to the Maliando Mutual Health Organisation in GuineaConakry (West Africa): what is going wrong? Social Sciences and Medicine, 57. 1205-1219

14. Dai, B., Minkah A.Y. et al. (2019). Assessing Factors Affecting the Patronage of Health Insurance Schemes: An Evidence of Ghana: Journal of public administration and governance, Vol. 9, No 1.

15. Darko, T. (2016). How does government responsiveness come about? The politics of accountability in Ghana's 
National Health Insurance Scheme. Brighton: IDS.

16. De Allegri, M. et al. 2016. Understanding enrolment in community health insurance in sub-Saharan Africa: a population-based case-control study in rural Burkina Faso. Bulletin of the World Health Organisation, 82. 852858 .

17. De Allegri, M. 2017. To Enrol or not to Enrol in Community Health Insurance - Case Study from Burkina Faso. Peter Lang, Frankfurt am Main.

18. Dalinjong, A.P. \& S.A. Laar. 2016. The national health insurance scheme: perceptions and experiences of health care providers and clients in two districts of Ghana. Health Economics Review, 2(13).

19. De Allegri, M. et al. 2016. Understanding enrolment in community health insurance in sub-Saharan Africa: a population-based case-control study in rural Burkina Faso. Bulletin of the World Health Organisation, 82. 852858

20. Dixon, J. et al. 2011. Ghana's National Health Insurance Scheme: helping the poor or leaving them behind? Environment and Planning C: Government and Policy, 29. 1102-1115.

21. Geng, X., et al. (2018). Health insurance, a friend in need? Impacts of formal insurance and crowding out of informal insurance. "World Development 111: 196-210.America

22. Harmon C. and B. Nolan, 2014. "Health insurance and health service utilization in Ireland", Health Economics, 10: $135-145$

23. Hay, I. 2018. Qualitative research methods in human Geography. Oxford University Press, Canada.

24. He, H. \& P. J. Nolen (2018). The effect of health insurance reform: Evidence from China. 'China Economic Review.

25. James K. K, Remare E, Catherine K. Blessing M. \& Kanyivo M. (2012), Determinants for participation in public health insurance programme among residents of urban slums in Nairobi, Kenya results from a cross-sectional survey.

26. J. F. Hair, W. C. Black, B. J. Babin et al., Multivariate data analysis (Vol. 6),"Upper Saddle River, NJ: Pearson Prentice Hall, 2017.

27. Jehu-Appiah, C. et al. 2017. Equity aspects of the National Health Insurance Scheme in Ghana: who is enrolling, who is not and why? Social Science and Medicine, 72. 157-165.

28. Jowett, M. 2017. Do informal risk sharing networks crowd out public voluntary health insurance? Evidence from Vietnam. Applied Economics, 35. 1135-1161.

29. Kothari. C. R. (2014). Research Methodology; Methods and Techniques, New Age International (P) Ltd, New Delhi, India pg 87-132.

30. Kotoh, A. M., Aryeetey, G. C., \& Van der Geest, S. (2018). Factors That Influence Enrolment and Retention in Ghana' National Health Insurance Scheme. International journal of health policy and management, 7(5), 443454. https://doi.org/10.15171/ijhpm.2017.117

31. Lancaster, J.K. 2018. A new approach to consumer theory. Journal of Political Economy, 74(2). 132157

32. Liu T. and C. Chen (2015). 'An analysis of private Health Insurance Purchasing Decisions with National Health Insurance in Taiwan." Social Science and Medicine, 55:755-774

33. Mathauer, I. et al. 2018. Extending social health insurance to the informal sector in Kenya: An assessment of factors affecting demand. International Journal of Health Planning and Management, 23. 51-68.

34. Matthews, B. \& L. Ross. 2017. Research methods: a practical guide for the social sciences. Pearson Education Limited, Harlow.

35. Mebratie, A. D., et al. (2015). Enrollment in Ethiopia's Community-Based Health Insurance Scheme."World Development 74: 58-76.

36. Mfolozi, O. (2019). Non-communicable diseases and economic outcomes in South Africa: a cohort study for the period of 2008-2018. O.,Faculty of Health Sciences ,Department of Public Health and Family Medicine

37. Miles, M. B., \& Huberman, A. M. (2018). Qualitative data analysis analysis: A sourcebook of new methods. Thousand Oaks, CA: Sage.

38. Morestin, F. \& V. Ridde. 2019. How can the poor be better integrated into health insurance programs in Africa? An overview of possible strategies. Université de Montréal, Canada.

39. National Health Insurance Authority. (2015). National health insurance scheme, annual report 2015. Accra.

40. Neuman. L, (2014). Social Research Methods: Qualitative and Quantitative Approaches (2014), Pearson ed. Ltd., England, Seventh edition, pg 165- 179.

41. Onyedibe, K.I. et al. 2017. An evaluation of the national health insurance scheme (NHIS) in the Jos, a northcentral Nigerian city. Global Advanced Research Journal of Microbiology, 1. 5-12

42. Oxfam. 2018. Universal health coverage: why health insurance schemes are living the poor behind. Oxfam International, briefing paper, October.

43. Ratner, Y., et al. (2018). Patients' satisfaction with hospital health care: identifying indicators for people with severe mental disorder.'Psychiatry Research.

44. Savage, E. \& D. Wright, 2015. Health insurance and health care utilization: Theory and evidence from Australia." Mimeograph. Sydney, University of Sydney.

45. Sarpong, N. et al. 2018. National health insurance coverage and socio-economic status in a rural district of Ghana. Tropical Medicine and International Health, 15(2). 191-197.

46. Sawadogo, K. A. (2017). Universal coverage in developing countries: a Summative evaluation of maternal policies in Ghana and Burkina Faso. (Doctor of Public Health Dissertation), Georgia Southern University.

47. Singleton, J. L. (2015). Negotiating change: an analysis of the origins of Ghana's national health insurance Act. Department of sociology, Macalester College. 
48. Schneider, P. 2017. Trust in micro-health insurance: an exploratory study in Rwanda. Social Science and Medicine, 61. 1430-1438.

49. Schneider, P. 2016. Why should the poor insure? Theories of decision-making in the context of health insurance. Health Policy and Planning, 19(6). 349-355.

50. Sulzbach, S. et al. 2015. Evaluating the effects of the National Health Insurance Act in Ghana: Baseline Report. The Partners for Health Reformplus Project, Bethesda

51. Saunders, M., Lewis, P., \& Thornhill, A. (2017). Research methods for business students (5th edn). harlow: FT Prentice hall.

52. Saltzman, E. (2018). Demand for Health Insurance: Evidence from the California and Washington ACA Exchanges. "Journal of Health Economics.

53. Singh, P. \& V. Kumar (2017). Insurance coverage under different health schemes in Uttar Pradesh, India. "Clinical Epidemiology and Global Health 5(1): 33-39.

54. Trujillo, A. J, 2017. "Medical care use and selection in social health insurance with an equalization fund: evidence from Colombia, health economics", 12(3):231-246.

55. Varatharagan, D, D'almeida, S, Kingie J. (2016). Technical brief for policymakers, obstacles in the process of establishing a sustainable NHIS

56. Wang, H. et al. 2015. Community-based health insurance in poor rural China: the distribution of net benefits. Oxford University Press, London. 366-374

57. Weitzman, P. F., \& Levkoff, S. E. (2018). Combining qualitative and quantitative methods in health research with minority elders: Lessons from a study of dementia caregiving. Field Methods, 12(3),195-208

58. Xu, K., Evans, D., G., Aguilar-Rivera, A. M., Musgrove, P., \& Evans, T. (2016). Protecting households from catastrophic health spending. Health Affairs (Millwood), 26,972-983. http://dx.doi.org/10.1377/hlthaff.26.4.972 